\title{
Nanoparticle Tactics for the Oral Delivery of Insulin in Alloxan- Induced Hyperglycemia in Rat (Rattus norvegicus domestica) Model
}

\author{
Ahmed Weli Hussein Osman ${ }^{1,2}$, Rakibul Islam ${ }^{1}$, Md. Bazlar Rashid ${ }^{1}$, Abdiaziz Idiris Mohamud ${ }^{2,3 *}$ and \\ Pravin Mishra ${ }^{4}$
}

${ }^{1}$ Department of Physiology and Pharmacology, Faculty of Veterinary and Animal Science, Hajee Mohammad Danesh Science and Technology University, Dinajpur, Bangladesh; ${ }^{2}$ Faculty of Veterinary Science, Benadir University, Mogadishu, Somalia; ${ }^{3}$ Department of Medicine, Faculty of Veterinary Science, Bangladesh Agricultural University, Mymensingh-2202, Bangladesh; ${ }^{4}$ Faculty of Veterinary Science, Bangladesh Agricultural University, Mymensingh-2202, Bangladesh.

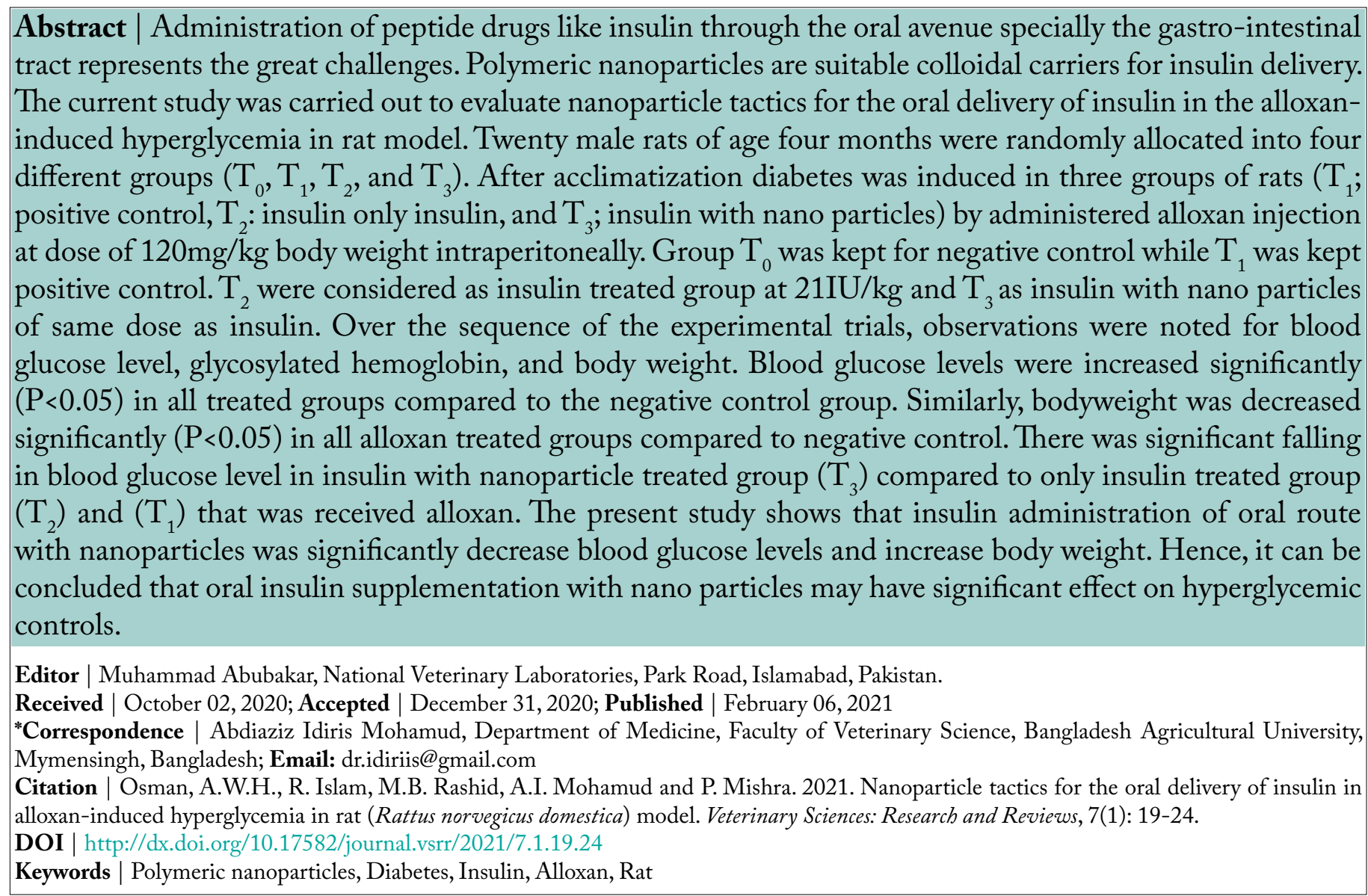

\section{Introduction}

$\mathrm{D}$ abetes is a very serious disease that has affected the health of every society, family, and individuals around the globe. It is one among the top ten causes of death globally and 1.6 million people died in 2016 by diabetics (WHO, 2018). In 2019, global health expenditure on diabetes was $\$ 760$ billion and expected to rise up to $\$ 845$ billion in 2045 (Elflein, 2019). Diabetes are of many types but type 1 diabetes, type 2 diabetes, and gestational diabetes are considered as the most common (NIDDK, 2016). 
The international diabetes federation has stated the global, national, and regional occurrence of diabetes from the year 2000 (Saeedi et al., 2019). The insulin hormone is used to manage diabetes normally by an administered subcutaneous route that controls blood glucose level but around 60\% of patients fail to maintain long term hyperglycemic control (Saaddine et al., 2006). Resistance to injectable insulin has been identified as a major reason for clinical inertia and lack of achievement of target glycemic goals (Balasubramanyam et al., 2013). The patients fear the harden of insulin therapy, associated hypoglycemia, and increases weight gain. Patients expect the development of oral insulin as it will be easy administration, more convenient, and lead to better glycemic control (Mukhopadhyay et al., 2012). Taken of therapeutic peptide drugs such as insulin via the oral route such as the gastrointestinal tract enzymes are one of the main challenges. Colloidal drug carriers have been advanced for controlled drug release and epitomize an exciting method to increase the acceptance and passage of peptide drugs such as insulin via oral route (Cui et al., 2006). Polymeric nanoparticles (NP) are appropriate colloidal carriers for insulin delivery and several examinations have been implemented to determine appropriate route of administrations (Barenholz, 2001). Polymeric NPs are solid colloidal nanocarriers that provide controlled release of peptides depending on the surface modifications by biodegradable polymers.

Chitosan (CS), a hydrophilic natural polymer, has been used in protein and peptide encapsulated NP formulation for its exceptional appearances including biocompatibility, biodegradability and mucoadhesivity (Pan et al., 2002; Ding et al., 2006). Therefore, the current study was carried out to evaluate the nanoparticle tactics for the oral delivery of insulin in alloxan-induced hyperglycemic rat model, to determine the efficacy of nanoparticle with insulin in the alloxan induced diabetic rat on live and blood glucose level and glycated hemoglobin, and to investigate the effect of nanoparticle with insulin on live body weight in alloxan-induced diabetic rats.

\section{Materials and Methods}

\section{Preparation of house}

The experimental shed was swept and washed with tap water followed by disinfection and air drying. All utensils required for the experiment such as feeder, water bottle, micro tube, syringe, needle, etc., were collected and the shed was properly designed with adequate ventilation.

\section{Experimental animal and design}

Twenty male rats (Rattus norvegicus domestica) of 30 dayswere purchased from International Centre for Diarrheal Disease Research, Bangladesh (ICDDR, B), Mohakhali, Dhaka and the rats were brought to the shed prepared at the laboratory of Hajee Mohammad Danesh Science and Technology University, Dinajpur, Bangladesh, and divided into four different groups having 5 rats in each group randomly. The divided groups were designated as $\mathrm{T}_{0}$ (Control no diabetes), $\mathrm{T}_{1}$ (Control of diabetes), $\mathrm{T}_{2}$ (Diabetes with the insulin-treated group), and $\mathrm{T}_{3}$ (Diabetes treated of insulin with nanoparticles). In each group, feed and water were provided ad-libitum.

In $T_{0}$ group, rats were administered with saline water orally. Bodyweight and blood glucose were recorded at day 0 (pre-treatment) before and after meal in the interval of seven days within 21 days at the same intervals with other groups. In $\mathrm{T}_{1}$ group, after acclimatization of body weight, level of blood glucose was measured after $18 \mathrm{hrs}$. of starvation then alloxan was induced by intraperitoneal injection of $120 \mathrm{mg} / \mathrm{kg}$ body weight (Kuete, 2017). In $\mathrm{T}_{2}$ group, blood glucose level and body weight were measured; similarly, after of starvation then alloxan monohydrate was injected at a same dose of $\mathrm{T}_{1}$ group. After 32 hours of alloxan monohydrate injection, diabetes was confirmed. Later, insulin was fed orally at a dose of $21 \mathrm{Unit} / \mathrm{kg}$ body weight for 21 days. During the treatment of insulin, body weights and level of blood glucose were recorded in the interval of 7 days for 21 days. In $T_{3}$ group, as above mentioned after checking blood glucose level and body weight before and after meal, and starvation then alloxan was injected as in $T_{1}$ group. Diabetes was confirmed as done in $\mathrm{T}_{2}$ group. After that insulin with nanoparticle was fed orally at a dose of $21 \mathrm{Unit} / \mathrm{Kg}$ body weight for 21 days. During the treatment of insulin with nanoparticles body weights and level of blood glucose were recorded at an interval of seven days for 21 days.

Collection, preparation and administration of insulin with nanoparticles

Chitosan, sodium tripolyphosphate was purchased from the Sigma-Aldrich in Germany, while distilled water, acetic solution and magnetic stirrer were 
available in the laboratory.

\section{Preparation of insulin with nanoparticles}

Insulin with nanoparticles was prepared according to ionotropic gelation method (Aktaş et al., 2005) by dissolving $4.375 \mathrm{mg}$ of chitosan in $2.5 \mathrm{~mL}$ of the acetic acid aq. solution to attain concentrations of 1.75 $\mathrm{mg} / \mathrm{mL}$ and subsequently $1 \mathrm{mg}$ of tripolyphosphate was dissolved in $2.5 \mathrm{~mL}$ of distilled water to get concentrations of $0.4 \mathrm{mg} / \mathrm{ml}$. The solutions were mixed using magnetic stirring at room temperature. $5 \mathrm{~mL}$ of insulin was added to the tripolyphosphate solution under slowly stirring at room temperature to obtain concentrations of $7.5 \mathrm{ml}$. Insulin with nanoparticles was prepared by adding premixed solutions of TPPinsulin drop wise to $2.5 \mathrm{~mL}$ of chitosan solution at room temperature until a stable colloidal suspension was formed spontaneously under gentle magnetic stirring.

\section{Administration of insulin with nanoparticle}

Insulin with nanoparticle was given to the rats through the oral route by using syringes at a dose of 21IU for 21 days.

\section{Collection, storage, and administration of insulin}

Insulin human USP (rDNA) was purchased from the local market in Dinajpur and it was stored at $4^{\circ} \mathrm{C}$ in a refrigerator for a day and it was given it orally to the rats at a dose of $21 \mathrm{IU} / \mathrm{kg}$ for 21 days.

\section{Recording of different parameters}

Blood glucose level: To measure the level of blood glucose of rats, blood samples were collected at 7 days interval for 21 days on 0,7 th, 14th, and 21st day. The rat was held at the base of the neck, after confirmed that the rat is not able to escape, the tip of the tail was pinched with a needle to bring the blood. After that the blood is coming out of the tail then the blood was put on the strip in sugar check and the blood glucose meter was active to read the level of blood glucose of the rat.
Determination of glycosylated haemoglobin test (HbA1c): To determine the glycosylated haemoglobin of each group of the rat's blood samples were collected at the end of the experiment and were transported to the diagnostic center to determine the level of glycosylated hemoglobin in each rat by using automatic machine analyzer.

Recording of body weight: Bodyweight of all groups were recorded before the treatment at Day 0 and during the treatment period on $7^{\text {th }}, 14^{\text {th }}$, and $21^{\text {st }}$ day using digital electric balance.

\section{Statistical analysis}

All results are expressed as mean $\pm \mathrm{SD}$. The groups were compared using SPSS version 22 and the results were considered statistically significant when at $\mathrm{p}<$ 0.05. Analysis of variance (ANOVA) was done to determine the significance between groups.

\section{Results and Discussion}

The present study was carried out to determine the nanoparticle tactics for the oral delivery of insulin in alloxan-induced hyperglycemic rat model. The results and discussions of all experiments were presented below:

\section{Effects of insulin with nanoparticle on blood glucose level in alloxan induced byperglycemic rat model}

Blood glucose level ( $\mathrm{mmol} / \mathrm{L})$ was decreased in insulin with nanoparticles treated group. The level of blood glucose of different groups of rats is shown in Table 1 . The study revealed that blood glucose level was low in group $T_{3}$, which was treated using insulin with nanoparticles compared to $\mathrm{T}_{2}$ group which was treated only using insulin with the same a dose at 21.IU/kg.

The effect of insulin with nanoparticles at a dose of 21 $\mathrm{IU} / \mathrm{kg}$ body weight in lowering blood sugar showed a statistically significant compared with the $\mathrm{T}_{2}$ group.

Table 1: Effects of insulin with nanoparticle on blood glucose level in alloxan induced byperglycemic rat model.

$\begin{array}{llllll}\text { Group } & \mathbf{T}_{\mathbf{0}} & \mathbf{T}_{\mathbf{1}} & \mathbf{T}_{\mathbf{2}} & \mathbf{T}_{3} & \text { Level of significance } \\ \text { Day 0 }(\text { mean } \pm \mathrm{SD}) \mathrm{mmol} / \mathrm{L} & 4.74 \pm 0.95 & 5.98 \pm 1.02 & 4.69 \pm 1.25 & 5.63 & \mathrm{NS} \\ \text { Day 7 }(\mathrm{mean} \pm \mathrm{SD}) \mathrm{mmol} / \mathrm{L} & 5.81 \pm 0.75 & 22.07 \pm 5.08 & 17.12 \pm 5.75 & 13.37 \pm 4.38 & * * \\ \text { Day 14 }(\mathrm{mean} \pm \mathrm{SD}) \mathrm{mmol} / \mathrm{L} & 5.0 \pm 0.76 & 22.82 \pm 5.14 & 17.37 \pm 5.14 & 12.69 \pm 4.09 & * * \\ \text { Day } 21(\mathrm{mean} \pm \mathrm{SD}) \mathrm{mmol} / \mathrm{L} & 4.56 \pm 0.86 & 19.63 \pm 6.27 & 16.55 \pm 3.71 & 11.56 \pm 4.76 & * *\end{array}$

**indicates significant at $P \leq 0.01$, and NS: Non-significant.

June 2021 | Volume 7 | Issue 1 | Page 21 
At a dose of 14 IU insulin $/ \mathrm{kg}$, rats exhibited a huge loss in glucose than was gained using a control insulinchitosan solution. An even greater decline in glucose levels was noticedby increasing the nanoparticle dose to $21 \mathrm{U}$ insulin/kg. Bowman and Leong (2006) theorize that "chitosan nanoparticles may defend insulin from gastrointestinal degradation and also improve uptake through muco-adhesion and/or permeation improvement". Nanoparticles protect proteolytic enzymes that destroy insulin when administered orally. The level of blood glucose was highly decreased in the treatment of insulin with nanoparticles. The blood sugar level is almost coming to the normal levels. The present results agree with other results too (Lee et al., 2004; Serpe et al., 2004; Colonna et al., 2008). The result of this study also agrees with Grenha et al. (2008). Gan and Wang (2007) described that nanoparticles reduced blood glucose level of streptozotocin-induced diabetic rats when it provided orally at insulin doses of $50 \mathrm{U} / \mathrm{kg}$ and/or $100 \mathrm{U} / \mathrm{kg}$. The result of this study indicates that a dose of 21 IU/ $\mathrm{kg}$ of insulin with nanoparticles might be a beneficial adjuvant for oral hyperglycemic agents in an alloxan induced diabetes. Similarly, Sarmento et al. (2007) described that nanoparticles with insulin massively increase intestinal absorption for administration of oral insulin in their study. Streptozotocin induced hyperglycemic rat nanoparticles were decreased serum glucose levels at different doses of insulin of 50 and $100 \mathrm{IU} / \mathrm{kg}$ up to 59 and $55 \%$, respectively. Inchaurraga et al. (2020) showed that nanoparticles were lowered the blood glucose level in hyperglycemic rats at a dose of $50 \mathrm{IU} / \mathrm{kg}$ up to $20 \%$ of their basal glucose levels.

\section{Effects of insulin with nanoparticle on glycosylated} hemoglobin in alloxan induced byperglycemic rat model

The results obtained from the diagnosis of glycosylated hemoglobin (HbA1c) among experimental animals were concluded that negative control $\mathrm{T}_{0}$ was the lowest in glycosylated hemoglobin while positive control $\mathrm{T}_{1}$ was the highest in the glycosylated hemoglobin.

In the treatment control groups, the glycosylated hemoglobin was the lowest at the insulin with nanoparticles group $\mathrm{T}_{3}$, while insulin-treated group $\mathrm{T}_{2}$ was the highest in the glycosylated hemoglobin (Figure 1). Afify et al. (2019) described that ZnONPs was reduced glycated hemoglobin significantly compared to diabetic group. Alkaladi et al. (2014) indicated that decline in sugar level of blood and increased significantly for the level of insulin in hyperglycemic rats which were treated with $\mathrm{ZnONPs}$.

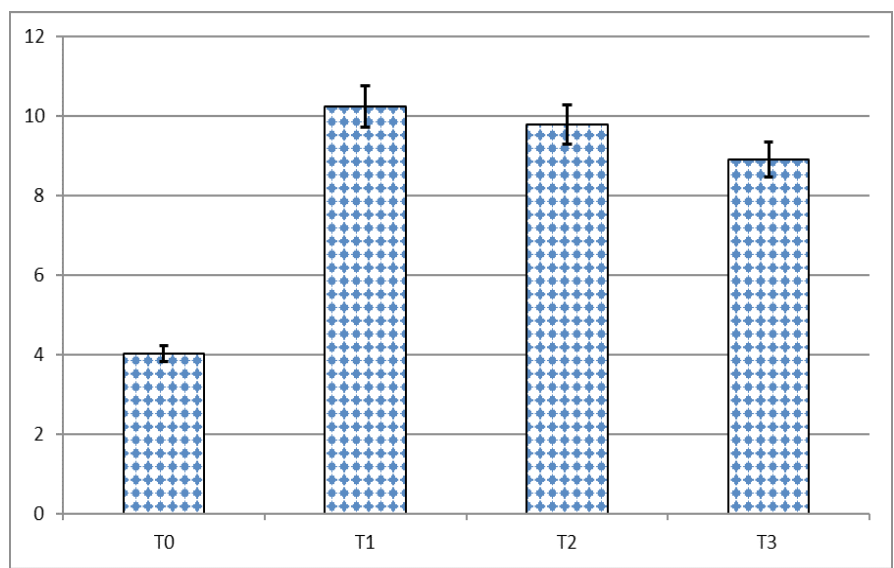

Figure 1: Effects of insulin with nanoparticle on glycosylated hemoglobin in alloxan induced hyperglycemic rat model.

\section{Effects of insulin with nanoparticles on body weight in alloxan induced byperglycemic rat model}

The percentage of body weight gain was increased over 21 days in the group $\mathrm{T}_{3}$ following oral administration of insulin with nanoparticles at $21 \mathrm{IU} / \mathrm{kg}$ while the insulin-treated group $T_{2}$ were decreased in the bodyweight at $7^{\text {th }}, 14^{\text {th }}$ and $21^{\text {st }}$ day as it was described in (Figure 2). Lenzen (2008) found that diabetic rats that were not treated exhibit massive decrease in their body weight compared to the control rats. Kasetti et al. (2010) also showed that increased insulin levels in hyperglycemic rats when they are treated selenium nanoparticles hence protected weight loss. Also, this study indicated that $T_{1}$ (positive control/ control with diabetic) were showed remarkable loss in body but $\mathrm{T}_{3}$ (nanoparticles with insulin treated group) increased body weight after treated nanoparticles with insulin. Therefore, nanoparticles might be better in the control of diabetes.

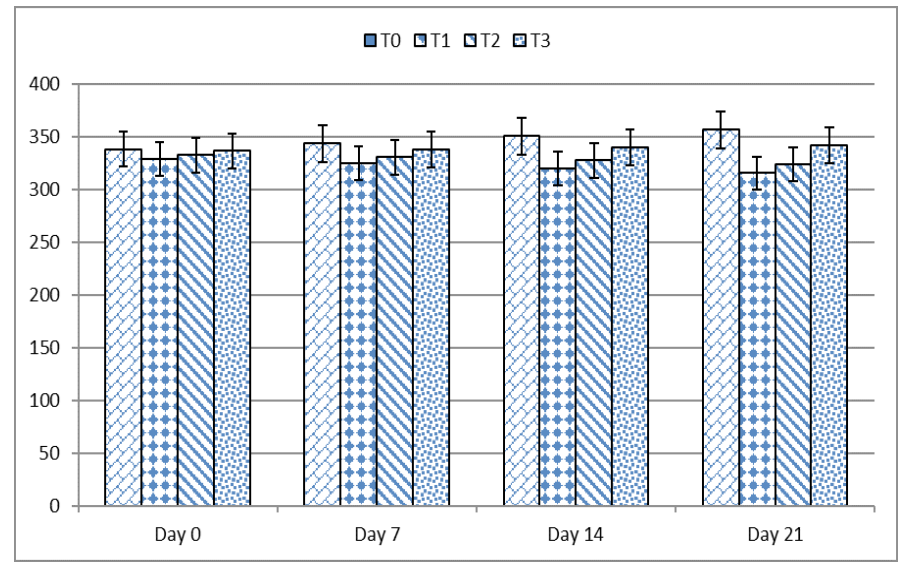

Figure 2: Effects of insulin with nanoparticle on body weight in alloxan induced byperglycemic rat model. 


\section{Conclusions and Recommendations}

The present study was concluded that insulin with nanoparticles showed better results in reducing the level of blood glucose in alloxan-induced diabetic rats after administration orally at $21 \mathrm{IU} / \mathrm{kg}$. A similar dose of insulin was shown that less effective when administered orally in alloxan-induced diabetics due to insulin degradation by proteolytic enzymes and lack of transport across the intestinal epithelium. Nanoparticles enhance the uptake and transport facility of peptide drugs such as insulin during oral administration. Therefore, it is recommended further research to be done on different types of nanoparticles with different protein hormones.

\section{Acknowledgements}

The authors would like to acknowledge the lab mates who helped during the research works.

\section{Novelty Statement}

The study showed the positive effects of insulin administration via oral route with nanoparticles. Insulin with nanoparticle significantly decrease blood glucose levels and increase body weight, which helps in maintaining healthy life.

\section{Author's Contribution}

AH performed the research and wrote original draft. RI supervise the study, provide critical comments and review the manuscript. MBR co-supervise the study and provide critical comments and review the manuscript. AIM and PM review the original draft, prepare the final manuscript and provide critical comments. All authors read the manuscript and agree to be responsible for any aspect of the manuscript.

\section{Conflict of interest}

The authors have declared no conflict of interest.

\section{References}

Afify, M., Samy, N., Hafez, N.A., Alazzouni, A.S., Mahdy, E.S., El Mezayen, H.A. and Kelany, M.M., 2019. Evaluation of Zinc-oxide nanoparticles effect on treatment of diabetes in streptozotocin-induced diabetic rats. Egypt. J.
Chem., 62(10): 1771-1783.

Aktaş, Y., Andrieux, K., Alonso, M.J., Calvo, P., Gürsoy, R.N., Couvreur, P. and Çapan, Y., 2005. Preparation and in vitro evaluation of chitosan nanoparticles containing a caspase inhibitor. Int. J. Pharm., 298(2): 378-383. https://doi. org/10.1016/j.ijpharm.2005.03.027

Alkaladi, A., Abdelazim, A.M. and Afifi, M., 2014. Antidiabetic activity of zinc oxide and silver nanoparticles on streptozotocin-induced diabetic rats. Int. J. Mol. Sci., 15(2): 2015-2023 .https://doi.org/10.3390/ijms15022015

Balasubramanyam, M., Narayanan, N., Mohan, V., Anjana, R. and Bindu, M., 2013. Nanotechnology based oral delivery of insulin a retrospect. Int. J. Pharm. Anal. Res., 2(4): 144150.

Barenholz, Y., 2001. Liposome application: Problems and prospects. Curr. Opin. Colloid Interface Sci., 6(1): 66-77. https://doi. org/10.1016/S1359-0294(00)00090-X

Bowman, K. and Leong, K.W., 2006. Chitosan nanoparticles for oral drug and gene delivery. Int. J. Nanomed., 1(2): 117-128. https://doi. org/10.2147/nano.2006.1.2.117

Colonna, C., Conti, B., Perugini, P., Pavanetto, F., Modena, T., Dorati, R., Iadarola, P. and Genta, I., 2008. Ex vivo evaluation of prolidase loaded chitosan nanoparticles for the enzyme replacement therapy. Eur. J. Pharm. Biopharm., 70(1): 58-65. https://doi.org/10.1016/j. ejpb.2008.04.014

Cui, F., Shi, K., Zhang, L., Tao, A. and Kawashima, Y., 2006. Biodegradable nanoparticles loaded with insulin-phospholipid complex for oral delivery: preparation, in vitro characterization and in vivo evaluation. J. Controlled Release, 114(2): 242-250. https://doi.org/10.1016/j. jconrel.2006.05.013

Ding, X., Alani, A.W. and Robinson, J.R., 2006. Extended-release and targeted drug delivery systems. In: David, B.T. and Paul, B. (eds), Remington: The science practice of pharmac, 21edn. Lipincott Williams Wilkins Philadelphia. pp. 939-40.

Elflein, J., 2019. Global healthcare expenditure due to diabetes in 2019 and 2045. Available at: https:/www.statista.com/statistics/241820/ estimated-global-healthcare-expenditures-totreat-diabetes/ (accessed 20 November 2020).

Gan, Q. and Wang, T., 2007. Chitosan nanoparticle 
as protein delivery carrier-systematic examination of fabrication conditions for efficient loading and release. Colloids Surf. B Biointerfaces, 59(1): 24-34. https://doi. org/10.1016/j.colsurfb.2007.04.009

Grenha, A., Remuñán-López, C., Carvalho, E.L. and Seijo, B., 2008. Microspheres containing lipid/chitosan nanoparticles complexes for pulmonary delivery of therapeutic proteins. Eur.j. Pharm. Biopharm., 69(1): 83-93. https:// doi.org/10.1016/j.ejpb.2007.10.017

Inchaurraga, L., Martínez-López, A.L., MartinArbella, N. and Irache, J.M., 2020. Zein-based nanoparticles for the oral delivery of insulin. Drug Deliv. Transl. Res., 10: 1601-1611. https://doi.org/10.1007/s13346-020-00796-3

Kasetti, R.B., Rajasekhar, M.D., Kondeti, V.K., Fatima, S.S., Kumar, E.G., Swapna, S., Ramesh, B. and Rao, C.A., 2010. Antihyperglycemic and antihyperlipidemic activities of methanol: Water (4:1) fraction isolated from aqueous extract of Syzygium alternifolium seeds in streptozotocin induced diabetic rats. Food Chem. Toxicol., 48(4): 1078-1084. https://doi. org/10.1016/j.fct.2010.01.029

Kuete, V., 2017. Thymus vulgaris. In: Kuete, V (eds), Medicinal spices and vegetables from Africa, $1^{\text {st }}$ edn. Academic Press. pp. 599-609. https://doi. org/10.1016/B978-0-12-809286-6.00028-5

Lee, D.-W., Powers, K. and Baney, R., 2004. Physicochemical properties and blood compatibility of acylated chitosan nanoparticles. Carbohydr. Polym., 58(4): 371-377. https://doi. org/10.1016/j.carbpol.2004.06.033

Lenzen, S., 2008. The mechanisms of alloxan-and streptozotocin-induced diabetes. Diabetologia, 51(2): 216-226. https://doi.org/10.1007/ s00125-007-0886-7

Mukhopadhyay, P., Mishra, R., Rana, D. and Kundu, P.P., 2012. Strategies for effective oral insulin delivery with modified chitosan nanoparticles: A review. Prog. Polym. Sci., 37(11): 1457-1475. https://doi.org/10.1016/j. progpolymsci.2012.04.004
NIDDK, 2016. What is diabetes? Available

at: https://www.niddk.nih.gov/healthinformation/diabetes/overview/what-isdiabetes (accessed 20 November 2020).

Pan, Y., Li, Y.-J., Zhao, H.-Y., Zheng, J.-M., Xu, H., Wei, G. and Hao, J.-S., 2002. Bioadhesive polysaccharide in protein delivery system: Chitosan nanoparticles improve the intestinal absorption of insulin in vivo. Int. J. Pharm., 249(1-2): 139-147. https://doi.org/10.1016/ S0378-5173(02)00486-6

Saaddine, J.B., Cadwell, B., Gregg, E.W., Engelgau, M.M., Vinicor, F., Imperatore, G. and Narayan, K.V., 2006. Improvements in diabetes processes of care and intermediate outcomes: United States, 1988-2002. Ann. Int. Med., 144(7): 465-474. https://doi.org/10.7326/0003-4819144-7-200604040-00005

Saeedi, P., Petersohn, I., Salpea, P., Malanda, B., Karuranga, S., Unwin, N., Colagiuri, S., Gaurigauta, L., A.A., M., Ogurtsova, K. and Shaw, J.E., 2019. Global and regional diabetes prevalence estimated for 2019 and projection for 2030 and 2015: Results from the International Diabetes Federation Diabetes Atlas, $9^{\text {th }}$ edition. Diab. Res. Clin. Pract., 157: 107843. https:// doi.org/10.1016/j.diabres.2019.107843

Sarmento, B., Ribeiro, A., Veiga, F., Sampaio, P., Neufeld, R. and Ferreira, D., 2007. Alginate/ chitosan nanoparticles are effective for oral insulin delivery. Pharm. Res., 24(12): 21982206. https://doi.org/10.1007/s11095-0079367-4

Serpe, L., Catalano, M.G., Cavalli, R., Ugazio, E., Bosco, O., Canaparo, R.,Muntoni,E.,Frairia,R., Gasco, M.R. and Eandi, M., 2004. Cytotoxicity of anticancer drugs incorporated in solid lipid nanoparticles on HT-29 colorectal cancer cell line. Eur. J. Pharm. Biopharm., 58(3): 673-680. https://doi.org/10.1016/j.ejpb.2004.03.026

WHO, 2018. The top 10 causes of death. Available at: https://www.who.int/news-room/factsheets/detail/the-top-10-causes-of-death (accessed 20 November 2020). 